\title{
The ankle cartilage cascade: incremental cartilage damage in the ankle joint
}

\author{
Jari Dahmen ${ }^{1,2,3} \cdot$ Jon Karlsson ${ }^{4} \cdot$ Sjoerd A. S. Stufkens ${ }^{1,2,3} \cdot$ Gino M. M. J. Kerkhoffs ${ }^{1,2,3}$
}

Received: 6 September 2021 / Accepted: 20 September 2021 / Published online: 5 October 2021

(c) European Society of Sports Traumatology, Knee Surgery, Arthroscopy (ESSKA) 2021, corrected publication 2021

\section{Abstract \\ Level of evidence Editorial, Level V.}

Keywords Osteochondral lesions of the talus $\cdot$ OLT $\cdot$ Cascade $\cdot$ Ankle $\cdot$ Cartilage

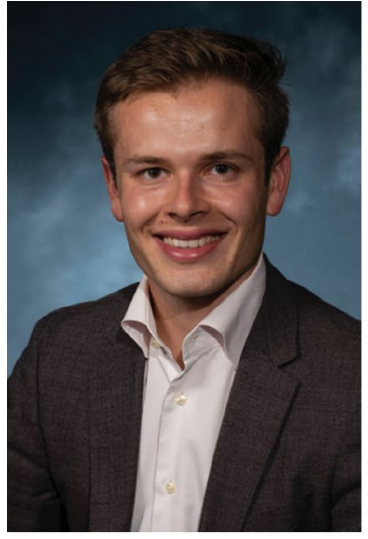

Jari Dahmen

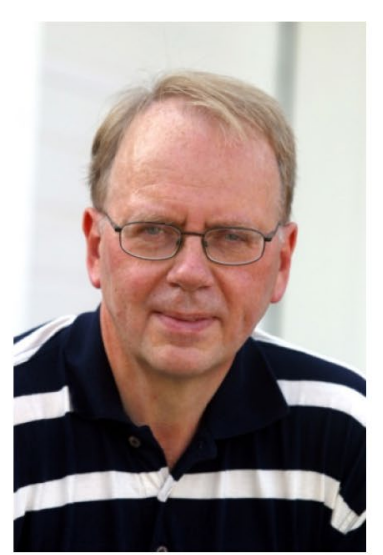

Jon Karlsson

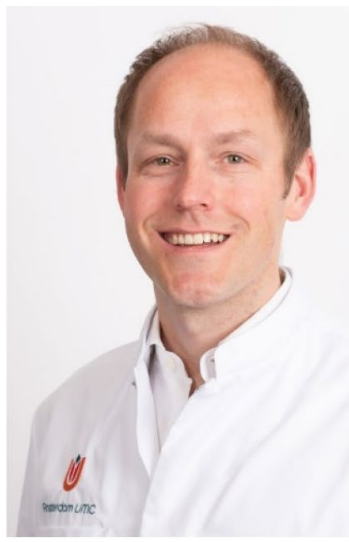

Sjoerd A.S. Stufkens

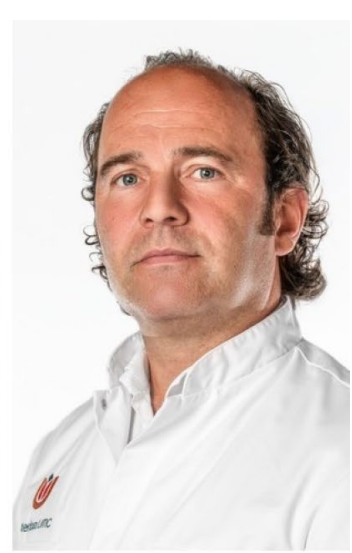

Gino M.M.J. Kerkhoffs
Jari Dahmen

j.dahmen@amsterdamumc.nl

$\bowtie$ Gino M. M. J. Kerkhoffs

g.m.kerkhoffs@amsterdamumc.nl

1 Department of Orthopaedic Surgery, Amsterdam Movement Sciences, Amsterdam UMC, Location AMC, University of Amsterdam, Meibergdreef 9, 1105 AZ Amsterdam, The Netherlands

2 Academic Center for Evidence Based Sports Medicine (ACES), Amsterdam UMC, Amsterdam, The Netherlands

3 Amsterdam Collaboration for Health and Safety in Sports (ACHSS), International Olympic Committee (IOC) Research Center, Amsterdam UMC, Amsterdam, The Netherlands

4 Department of Orthopaedics, Sahlgrenska University Hospital, Sahlgrenska Academy, Gothenburg University, Gothenburg, Sweden
Ankle sprains remain the most frequent injuries in sporting activities [7, 8, 36]. A few decades ago, ankle sprains were assumed to be injuries that were not associated with any substantial harm. However, the last 20 years have shown that they are not as harmless as thought, as depicted in the March Issue of the year of 2016 in this Journal: 'There is no simple lateral ankle sprain' (Fig. 1) [13, 14]. The development of cartilage lesions following an ankle sprain is certainly food for thought, thus sparking the idea of the current Editorial. The process of cartilage degradation in the ankle following an ankle injury resembles a waterfall or cascade. Each stage sets up or "pours down" into the next stage of cartilage damage in the ankle joint. 


\section{Asymptomatic superficial cartilage lesions}

An asymptomatic cartilage lesion of the ankle, not involving any damage to the subchondral bone plate, may arise from a traumatic event, such as an ankle sprain or fracture [3]. Microscopic cartilage lesions are mostly referred to as inert, and it is believed that these lesions will not progress into an osteochondral lesion neither end-stage osteoarthritis, nor will they become symptomatic due to the fact that cartilage is avascular and a-neural tissue $[16,17,28]$. As concluded by Mankin et al. in 1974, if superficial lacerations of articular cartilage are limited in size and depth, they will 'neither heal nor progress to more serious disorders' [16, 17]. This statement can be substantiated by a recent meta-analysis that showed that although the incidence of reported osteochondral damage after ankle sprain or fracture was high (namely 45\%), the proportion that may result in poor clinical outcomes (as a consequence of osteochondral damage or end-stage osteoarthritis) can be considered relatively low [5, 19, $26,33,37]$. This finding has further been described by several studies reporting good patient-reported mid- to long-term outcomes following ankle trauma (sprains and fractures) $[11,12]$. It must, however, be acknowledged that although Mankin et al. refer to the superficial lacerations as being relatively harmless or inert, it may well be the case that these superficial lesions contain microscopic cracks potentially inducive of the cartilage cascade as described and shown below [3].

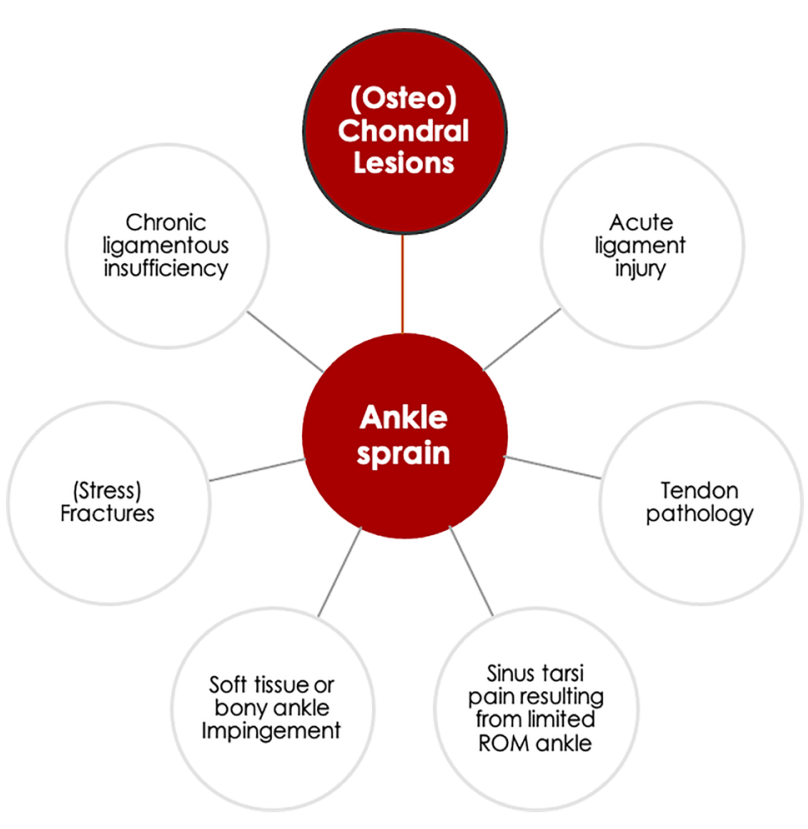

Fig. 1 Sequential pathologies after an ankle sprain

\section{Post-traumatic cartilage cracks with damage to the subchondral bone and post-traumatic chondrocyte apoptosis}

Cartilage lesions may become symptomatic after a traumatic event when (microscopic) cartilage cracks progress into the subchondral bone [3]. Consequently, these lesions will induce bleeding after which the lesion will either heal or fail to heal $[4,10,16-18,21]$. The failed healing induces a cascade of events as highlighted in Fig. 2. The first stage entails a cartilage crack with subchondral bone plate damage with an insufficient repair response, that subsequently leads to an osteochondral lesion, with the potential of leading to end-stage osteo-arthritis, either localized or of the whole joint $[6,27,32,34]$. The most interesting research question remains: why do some of the above-mentioned lesions heal while others do not?

Another entrance into the cascade is via chondrocyte apoptosis following, for example, intra-articular fractures $[2,15,20]$. A recent study by Blom et al. supports the theory of the Incremental Cartilage Damage (Fig. 2) in the ankle as part of the cascade [3]. In this study, Blom et al. investigated the presence of chondral damage after incremental single axial impact loads in ex-vivo ankle joint caprine models. After these single axial impact loads, the damage was assessed microscopically as well as through a contrast-enhanced high-resolution micro-computed tomography scan (micro-CT-scan). Furthermore, wholejoint biomechanics were assessed. Although no osteochondral damage was visible through the micro-CT-scan nor on the microscopic tests, changes were observed in the biomechanical behaviour of the joint following a single axial impact load. These changes can be a result of the alteration of the specific relative and absolute compositions and balance between proteoglycans, glycoproteins, (sulphated) glycosaminoglycans (sGAGs), and water content in the joint. Such biomechanical alternations as a result of impact load have also been observed in the knee [3, 9, 22, 25, 38].

\section{Large superficial or erosive cartilage lesion due to a post-traumatic status or biomechanical problem}

Another potential pathophysiological pathway is a large acute superficial or erosive chronic cartilage lesion caused by trauma or an underlying biomechanical problem in or around the ankle, such as malalignment, malunion after fracture or (chronic) ligament laxity. Altered pressure distribution, edge-loading and chronic erosion of the cartilage are related to repeated microtrauma due to chronic ligament laxity and may ultimately result in a deep cartilage lesion, as a 
Fig. 2 Cascade analogy, from sprain/fracture to end-stage osteo-arthritis

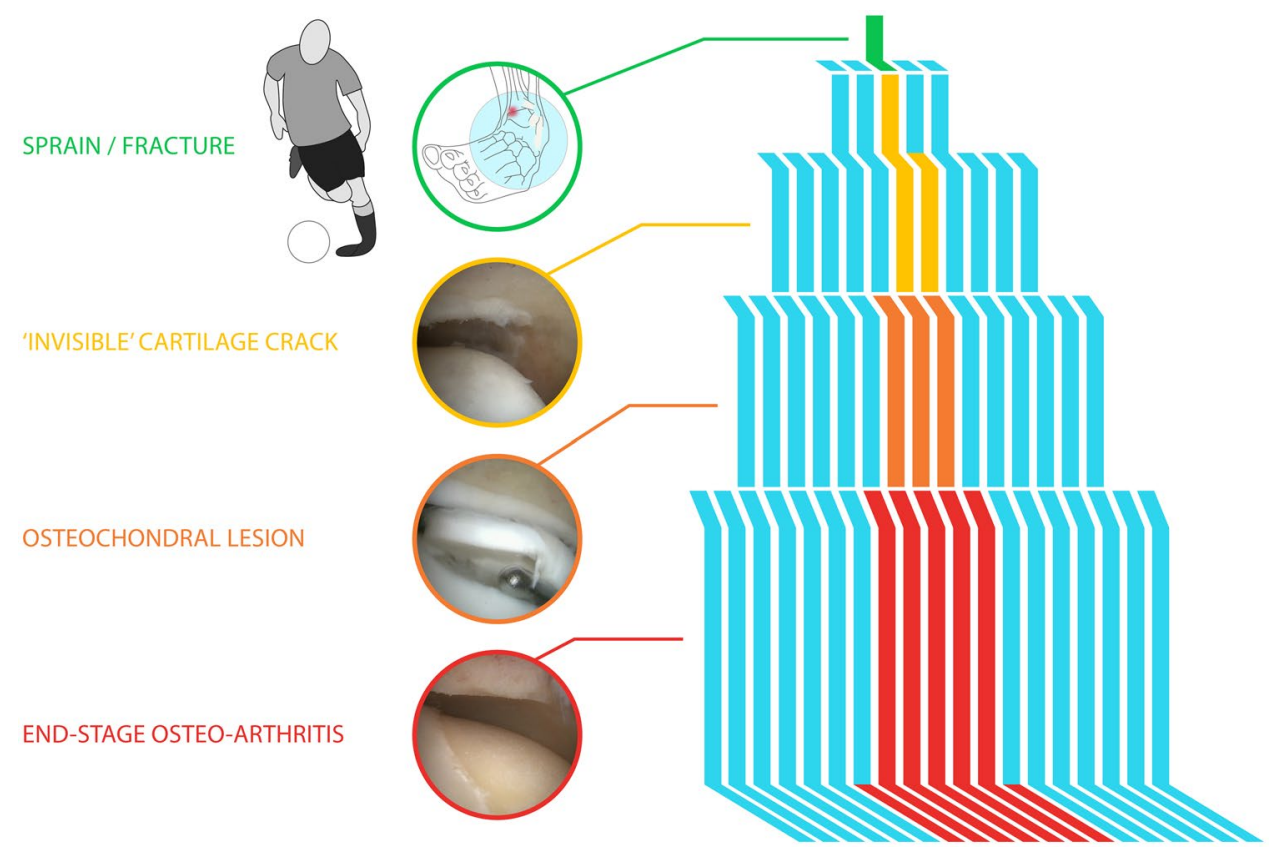

Take to work from the ankle cartilage cascade

Related to the description of the idea on the abovementioned cascades and the underestimated incidence rates of posttraumatic (osteo)chondral lesions, there might be different pathophysiological pathways that can induce cartilage damage and potentially lead to osteoarthritis of the ankle joint. Hence, more focus should be put on early detection and primary and secondary individualized preventive interventions to prevent cartilage damage in the earliest step of the cascade: the subclinical phase. This approach could allow for an early delay or even stop to the cartilage crack that leads to the waterfall of degeneration, and could prevent the development of osteochondral lesions and end-stage OA; two conditions with severe symptoms that affect the quality of life of the patient [1, 24]. Moreover, from a societal perspective, one can also state that this is a paramount undertaking, as we know from previous literature that end-stage $\mathrm{OA}$ is associated with high direct and indirect costs [12, 23]. To accomplish such goals as mentioned above, we need novel, sophisticated imaging tools [29-31] as well as innovations to cushion the joint so that we are able to diagnose and treat the cartilage damage at the early subclinical phase. [29-31]. Through presentation of the Ankle Cartilage Cascade, we hope to encourage future research to focus on the subclinical phase after ankle trauma, ultimately stalling the ongoing cascade in this phase to work towards prevention of end-stage ankle osteo-arthritis.

Acknowledgments Figure 2 was kindly produced by Marieke de Lorijn, Marsprine. 


\section{Declarations}

Conflict of interest All authors declare no conflict of interest for the present editorial.

\section{References}

1. Al-Mahrouqi MM, MacDonald DA, Vicenzino B, Smith MD (2018) Physical impairments in adults with ankle osteoarthritis: a systematic review and meta-analysis. J Orthop Sports Phys Ther 48:449-459

2. Anderson DD, Marsh JL, Brown TD (2011) The pathomechanical etiology of post-traumatic osteoarthritis following intraarticular fractures. Iowa Orthop J 31:1-20

3. Blom RP, Mol D, van Ruijven LJ, Kerkhoffs G, Smit TH (2019) A single axial impact load causes articular damage that is not visible with micro-computed tomography: an ex vivo study on caprine tibiotalar joints. Cartilage. https://doi.org/10.1177/1947603519 8763531947603519876353

4. Campbell CJ (1969) The healing of cartilage defects. Clin Orthop Relat Res 64:45-63

5. D'Hooghe P, Grassi A, Alkhelaifi K, Calder J, Baltes TP, Zaffagnini $S$ et al (2020) Return to play after surgery for isolated unstable syndesmotic ankle injuries (West Point grade IIB and III) in 110 male professional football players: a retrospective cohort study. Br J Sports Med 54:1168-1173

6. Delco ML, Kennedy JG, Bonassar LJ, Fortier LA (2017) Posttraumatic osteoarthritis of the ankle: a distinct clinical entity requiring new research approaches. J Orthop Res 35:440-453

7. Doherty C, Delahunt E, Caulfield B, Hertel J, Ryan J, Bleakley C (2014) The incidence and prevalence of ankle sprain injury: a systematic review and meta-analysis of prospective epidemiological studies. Sports Med 44:123-140

8. Ekstrand J, Krutsch W, Spreco A, van Zoest W, Roberts C, Meyer T et al (2020) Time before return to play for the most common injuries in professional football: a 16-year follow-up of the UEFA Elite Club Injury Study. Br J Sports Med 54:421-426

9. Fischenich KM, Button KD, DeCamp C, Haut RC, Donahue TL (2017) Comparison of two models of post-traumatic osteoarthritis; temporal degradation of articular cartilage and menisci. J Orthop Res 35:486-495

10. Fuller JA, Ghadially FN (1972) Ultrastructural observations on surgically produced partial-thickness defects in articular cartilage. Clin Orthop Relat Res 86:193-205

11. Gilley J, Bell R, Lima M, Butler B, Barrett JE, Patel M et al (2020) Prospective patient reported outcomes (pro) study assessing outcomes of surgically managed ankle fractures. Foot Ankle Int 41:206-210

12. Gribble PA, Bleakley CM, Caulfield BM, Docherty CL, Fourchet F, Fong DT et al (2016) Evidence review for the 2016 International Ankle Consortium consensus statement on the prevalence, impact and long-term consequences of lateral ankle sprains. Br J Sports Med 50:1496-1505

13. Kerkhoffs G, Karlsson J (2019) Osteochondral lesions of the talus. Knee Surg Sports Traumatol Arthrosc 27:2719-2720

14. Kerkhoffs GM, Kennedy JG, Calder JD, Karlsson J (2016) There is no simple lateral ankle sprain. Knee Surg Sports Traumatol Arthrosc 24:941-943

15. Kim HT, Lo MY, Pillarisetty R (2002) Chondrocyte apoptosis following intraarticular fracture in humans. Osteoarthr Cartil $10: 747-749$
16. Mankin HJ (1974) The reaction of articular cartilage to injury and osteoarthritis (first of two parts). N Engl J Med 291:1285-1292

17. Mankin HJ (1974) The reaction of articular cartilage to injury and osteoarthritis (second of two parts). N Engl J Med 291:1335-1340

18. Mankin HJ (1982) The response of articular cartilage to mechanical injury. J Bone Joint Surg Am 64:460-466

19. Martijn HA, Lambers KTA, Dahmen J, Stufkens SAS, Kerkhoffs G (2021) High incidence of (osteo)chondral lesions in ankle fractures. Knee Surg Sports Traumatol Arthrosc 29:1523-1534

20. McKinley TO, Borrelli J Jr, D'Lima DD, Furman BD, Giannoudis PV (2010) Basic science of intra-articular fractures and posttraumatic osteoarthritis. J Orthop Trauma 24:567-570

21. Meachim G, Roberts C (1971) Repair of the joint surface from subarticular tissue in the rabbit knee. J Anat 109:317-327

22. Nelson F, Billinghurst RC, Pidoux I, Reiner A, Langworthy M, McDermott M et al (2006) Early post-traumatic osteoarthritislike changes in human articular cartilage following rupture of the anterior cruciate ligament. Osteoarthr Cartil 14:114-119

23. Nwachukwu BU, McLawhorn AS, Simon MS, Hamid KS, Demetracopoulos CA, Deland JT et al (2015) Management of end-stage ankle arthritis: cost-utility analysis using direct and indirect costs. J Bone Joint Surg Am 97:1159-1172

24. Paget LDA, Tol JL, Kerkhoffs G, Reurink G (2021) Health-related quality of life in ankle osteoarthritis: a case-control study. Cartilage. https://doi.org/10.1177/1947603521102581419476035 211025814

25. Palmer AW, Guldberg RE, Levenston ME (2006) Analysis of cartilage matrix fixed charge density and three-dimensional morphology via contrast-enhanced microcomputed tomography. Proc Natl Acad Sci USA 103:19255-19260

26. Rellensmann K, Behzadi C, Usseglio J, Vosseller JT, Böcker W, Polzer $\mathrm{H}$ et al (2021) Acute, isolated and unstable syndesmotic injuries are frequently associated with intra-articular pathologies. Knee Surg Sports Traumatol Arthrosc 29:1516-1522

27. Saltzman CL, Salamon ML, Blanchard GM, Huff T, Hayes A, Buckwalter JA et al (2005) Epidemiology of Ankle arthritis: report of a consecutive series of 639 patients from a tertiary orthopaedic center. Iowa Orthop J 25:44-46

28. Sophia Fox AJ, Bedi A, Rodeo SA (2009) The basic science of articular cartilage: structure, composition, and function. Sports Health 1:461-468

29. Stornebrink T, Altink JN, Appelt D, Wijdicks CA, Stufkens SAS, Kerkhoffs G (2020) Two-millimetre diameter operative arthroscopy of the ankle is safe and effective. Knee Surg Sports Traumatol Arthrosc 28:3080-3086

30. Stornebrink T, Emanuel KS, Shimozono Y, Karlsson J, Kennedy JG, Kerkhoffs G (2020) A change in scope: redefining minimally invasive. Knee Surg Sports Traumatol Arthrosc 28:3064-3065

31. Stornebrink T, Stufkens SAS, Appelt D, Wijdicks CA, Kerkhoffs $\mathrm{G}$ (2020) 2-Mm diameter operative tendoscopy of the tibialis posterior, peroneal, and achilles tendons: a cadaveric study. Foot Ankle Int 41:473-478

32. Stufkens SA, Knupp M, Horisberger M, Lampert C, Hintermann B (2010) Cartilage lesions and the development of osteoarthritis after internal fixation of ankle fractures: a prospective study. $\mathrm{J}$ Bone Joint Surg Am 92:279-286

33. Sugimoto K, Takakura Y, Okahashi K, Samoto N, Kawate K, Iwai M (2009) Chondral injuries of the ankle with recurrent lateral instability: an arthroscopic study. J Bone Joint Surg Am 91:99-106

34. Taga I, Shino K, Inoue M, Nakata K, Maeda A (1993) Articular cartilage lesions in ankles with lateral ligament injury. An arthroscopic study. Am J Sports Med 21:120-126 (discussion 126-127) 
35. Valderrabano V, Hintermann B, Horisberger M, Fung TS (2006) Ligamentous posttraumatic ankle osteoarthritis. Am J Sports Med 34:612-620

36. Vuurberg G, Hoorntje A, Wink LM, van der Doelen BFW, van den Bekerom MP, Dekker R et al (2018) Diagnosis, treatment and prevention of ankle sprains: update of an evidence-based clinical guideline. Br J Sports Med 52:956

37. Wang DY, Jiao C, Ao YF, Yu JK, Guo QW, Xie X et al (2020) Risk factors for osteochondral lesions and osteophytes in chronic lateral ankle instability: a case series of 1169 patients. Orthop J Sports Med 8:2325967120922821
38. Wei L, Fleming BC, Sun X, Teeple E, Wu W, Jay GD et al (2010) Comparison of differential biomarkers of osteoarthritis with and without posttraumatic injury in the Hartley guinea pig model. J Orthop Res 28:900-906

39. Wolf CR, Mankin HJ (1965) The effect of experimental hemarthrosis on articular cartilage of rabbit knee joints. J Bone Joint Surg Am 47:1203-1210

Publisher's Note Springer Nature remains neutral with regard to jurisdictional claims in published maps and institutional affiliations. 